\title{
Animation + Agricultural Microbiology Insterdisciplinary VR Curriculum Development in the Background of Industry-Academia Collaborative Education
}

\author{
Xianzhi Tu${ }^{1}$, Jue Xin ${ }^{2}$, Rong Zhang ${ }^{3}$ \\ ${ }^{1}$ College of Arts, South China Agricultural University, Guangzhou, Guangdong, 510642 \\ ${ }^{2}$ College of Arts, South China Agricultural University, Guangzhou, Guangdong, 510642 \\ ${ }^{3}$ College of Horticulture, South China Agricultural University, Guangzhou, Guangdong, 510642
}

\begin{abstract}
Since the teaching in colleges and universities is divided into disciplines according to knowledge fields, so there is distinct boundary between disciplines in actual teaching, which leads to the lack of interdisciplinary thinking and cross-professional knowledge of students, and it also becomes difficult for colleges and universities to cultivate talents. The development of the new era places new demands on higher education. The construction of new liberal arts and new agricultural sciences requires innovative research on interdisciplinary research methods, talent training models, and research and development of the teaching content. VR virtual reality technology is used to carry out interdisciplinary research on animation teaching and agricultural microbiology teaching, and develop new curriculum, which can effectively enhance the effectiveness of teaching in various disciplines, and open up new teaching content and research ideas for animation and agricultural microbiology courses. Virtual reality technology and digital animation art provide an interactive and immersive teaching experience for the teaching and research of agricultural microbiology, and also inspire new ideas for teaching and research of new agricultural sciences. The content of agricultural microbiology provides research content for the creation of animation arts and expands the space for technology research and development. This article will discuss from the perspective of research background and research analysis, promote the development of interdisciplinary research in higher education, and also explore the research model of interdisciplinary curriculum development.
\end{abstract}

\section{Introduction}

The study of human can be divided into mechanical learning and meaningful learning. In mechanical learning, people are just struggling to memorize and recite, but in meaningful learning, they can transfer what they have learned to new situations. The real goal of education should be promoting knowledge transfer and meaningful learning [1]. The teaching in colleges and universities is classified according to disciplines, with majors as divisions, and students learn specialized knowledge. The teaching of agricultural microbiology has very strong professional characteristics. The observation objects involved in the teaching are very tiny. The teaching is limited by objective conditions, environment and equipment, which impedes the students' learning motivation and weakens the teaching effect of teachers [2]. It is difficult to put the teaching and research content which are affected by the season, restricted by conditions or potentially harmful into field teaching, so the teaching content is hard to be fully presented. The combination of animation based on VR virtual reality technology and the teaching content of agricultural microbiology can present the knowledge of microbiology in the form of interactive animation, so that the teaching conditions are no longer restricted by objective environment, and the teaching of agricultural microbiology can be more vivid and effective. Moreover, it can reduce potential risks and equipment investment [3]. The introduction of agricultural microbiological knowledge into animation teaching and research also provides new content for animation creation courses in the art discipline. South China Agricultural University has cooperated with Shenzhen Guotai'an Education and Technology Co., Ltd. in industry and academia to research the project of "VR Smart Education: Animation + VR Curriculum Development", combining the digital animation content of the art discipline with the agricultural microbiology content of the agricultural sciences, and to explore interdisciplinary research methods, develop curriculum content across arts and agricultural disciplines, and study new models of new liberal arts and new agricultural science construction. 


\section{Digital Animation + Agricultural Microbiology Interdisciplinary Research Background}

In recent years, the number of professional disciplines in universities has been increasing, the professional branches are becoming more and more refined, and the professional barrier relationship is gradually strengthened. There is a voice of opposition from experts and scholars, who believe that students trained in this model lack thinking competence and the width of knowledge. Students may enter the "dead end" [4] during the learning process. Generally speaking, the specialization of colleges and universities majors has become an inevitable trend, and students do have the problem of lacking a macro perspective of knowledge. Based on this, interdisciplinary research has become an inevitable trend, we ought to acquire new teaching and research inspiration from interdisciplinary processes, change traditional research thinking and models, and provide a new perspective for professional development.

There is also a lot of of interdisciplinary research in traditional teaching, but after careful study, most of them carry out related research activities in the mode of "crossing between sciences" and "crossing between arts". It has narrow professional span, and the students still have limited vision and knowledge [5]. "Crossing between arts and sciences" is not common in colleges and universities, mainly because of the strong professionalism of knowledge. Without the prior accumulation of professional knowledge, it is difficult for cross-disciplinary learning to keep up with the progress. However, "crossing between arts and sciences" is not impossible. The key is how to "cross", finding where the gaps between disciplines are, and how to solve the problems we need to solve. Scientific masters such as Planck, Leonardo da Vinci, and Einstein all excel in the fields of music and painting, and it in turn helps their scientific researches.

Agricultural microbiology is the basic content of agricultural disciplines. Conventional teaching is mostly displayed in text and pictures, which easily leads to deviations in understanding [6]. Taking Litchi Downy Blight as an example, litchi has obvious seasonal characteristics. When the same pathogens are applied to different litchi varieties, there are distinct differences in the action mechanism. The pathological characteristics of litchi, the growth process of Peronophythora litchi, and the study and research of action mechanism are greatly affected by the season and environment, which makes it difficult to carry out regular classroom teaching. The observation of the growth cycle of germs is also limited by experimental conditions, or some germs are highly infectious or harmful to human, the experimental teaching cannot be popularized. As a result, there are some discomforts and difficulties in students' understanding during the learning process, and they could not have three-dimensional imagination of the role of some microbes in agriculture. So this has become a constraint point in the teaching of agricultural microbiology and has weakened the learning effectiveness of students in the study of agricultural microbiology.

The main professional courses of the animation major in the digital animation arts discipline include virtual reality technology, animation, UI interface design, photography and other aspects. It is a highly integrated course [7]. The animation teaching focuses on cultivating students' innovative ability, practical ability and professional skills. However, in the actual teaching process, the lack of teaching cases and teaching content has caused the digital animation teaching in colleges and universities to be limited to basic skills. Students lack of flexible knowledge application capability, expanding research capability and technology research and development capability. According to the theory of interactive behavior in teaching, the degree of behavior involvement can significantly promote the effect of internal transfer and external expansion transfer of deep learning [8]. At present, there is a high demand for research and development of VR interactive technology, and there are few researches on this subject of art disciplines in colleges and universities. Students' VR technology application and research and development capabilities are insufficient to meet the social talent needs. Animation belongs to the cultural industry, and cultural innovation is the core driving force of the cultural industry. Due to the lack of innovative ability and narrow professional thinking, students' cultural creativity mostly comes from works that have been published and broadcast, and lacks new ideas.

The research of agricultural microbiology solves the problems in agricultural production from the perspective of microbial technology and promotes the development of agriculture. The research of digital animation makes creative expression with digital image technology from the perspective of arts and humanities [9]. The two majors seem to be unrelated, but with the in-depth development of VR smart education projects, we find that art has the function of binding the two. It is needed to further explore the characteristics of mutual promotion and motivation of art and agriculture. They have strong professional complementarity. The mutual development of digital animation and agricultural microbiology in teaching and scientific research is a new trend in the development of new liberal arts and new agricultural education. It is a new theme for the professional development put up by the social talent demand. Digital animation can enlarge the microcosm, and can show the growth states over a few years through clip compression within one minute, so that students of agricultural microbiology can directly see the process of the impact of microbes on agricultural crops, students can get rid of the limitation of agricultural microorganism observation time. Even in the non-litchi fruiting season, they can still learn the mechanism of litchi infection [10]. In the process of contacting agricultural microbiology, students of animation majors will also be inspired to use animation technology flexibly to form new solutions, open up new creative ideas, and make new creative achievements.

Turning new technology into the essential force of education can effectively enhance students' practical 
ability [11]. The interdisciplinary research on animation + agricultural microbiology is the core content and main practical results of the research on the "VR Smart Education: Animation + VR Curriculum Development" of the Ministry of Education's industry-academia collaborative education project. With the help of teachers and students engaged in agricultural microbiology research at the College of Horticulture, the teachers and students of animation major create digital animation videos, VR virtual simulation teaching software and other works with Phytophthora litchii as materials, which present a microscopic world that is hard to detect with naked eyes, enrich students' creative vision, and also cultivate the imagination, creativity and problem-solving ability of students majoring in animation. Interdisciplinary students of agricultural microbiology learn about microbiology through virtual simulation software, and understand the growth process and infection status of Phytophthora litchii. Digital animation + agricultural microbiology interdisciplinary research is the collision of wisdom between the two majors, providing a new direction for the teaching reform of the two majors.

\section{Animation + Agricultural Microbiology Interdisciplinary Research Analysis}

\subsection{Discarding the Old and Establishing the New, Reforming the Teaching Method}

The specialty of agricultural microbiology is strong in practice and the knowledge is difficult to learn, and students mainly rely on experimental observation to internalize the related knowledge during the learning process [12]. Carrying out experimental teaching to cultivate students' understanding and application ability has become a specific teaching cognition of this subject, but in real teaching process, students' experimental learning needs cannot be fully met. The main reasons are as follows:

First, experimental conditions are limited. The knowledge obtained by personal observation is often impressive, but the microbiology observation requires the use of equipment such as electron microscope, which is very expensive. Some equipment even cost tens of millions, making teachers and students worry about causing damage to the experimental equipment when they are using them, so most of the teaching are theoretical knowledge teaching.

Second, some research contents have high risks. Some microbial germs are extremely transmissible, and they cannot be brought out of the laboratory for teaching, which limits the experimental teaching. In addition, even if students can go to the laboratory for observation, due to the small number of equipment and the large number of professional students, the teaching activities are often carried out in small groups, each student can observe only a small amount of time, so they can hardly practice internalization, and the effectiveness of the teaching is very limited.

Third, teaching content is limited by course time. Agricultural microbial knowledge is mainly practice-oriented, and some research content is highly random. Part of the microbial knowledge learning process is limited by the microbial growth process, such as the occurrence of litchi pathology, the collection of microbial samples are limited by the natural environment such as weather and rain, and it has become a difficult point for experimental teaching to break through. Due to the limitation of the microbial growth cycle, the growth process and action cycle of some microbes are difficult to be reflected in teaching. Therefore, this project presents the growth process of litchi pathology and peronophythora litchii in multi-dimensions through interactive technology, virtual simulation animation demonstration and videos, making scientific research and teaching become more vivid.

The application of digital animation in the teaching of agricultural microbiology can realize the breaking of old and establishing of new, change the status of traditional teaching, solve the problems of professional teachers in teaching, and make up for the inconvenience of equipment usage and difficulty in observation during the teaching process[13]. Applying digital video to the observation and display of agricultural microbes can make the boring microbial images become interesting and vivid and use arts to process them on the basis of respecting facts. For example, in the observation of the growth of peronophythora litchii, it can be dynamically displayed through animation, highlighting the growth characteristics, making the teaching of agricultural microbiology more interesting, and the video can be displayed repeatably, so it is quite effective.

\subsection{Arts and Sciences Promoting Each Other}

The application of digital animation to the teaching of agricultural microbiology is not only beneficial to the teaching of agricultural microbes, but also very helpful to the professional teaching of animation. The introduction of agricultural microbiological content in the animation specialty teaching has expanded the content of animation teaching, cultivated students' ability to solve problems flexibly, and improved students' creative skills in the process of virtual simulation design[14]. The introduction of microbiological technology in the teaching of animation can train students to have the ability to participate in VR application development and the ability to solve problems flexibly, and understand how to cooperate with application developers for content development, which can make them better meet industry needs in the future.

For example, in the research process of this project, after comparing the characteristics of different varieties of litchi and testing with various methods, it was found that litchis are small in size, delicate in detail, their characteristics change quickly once they leave the plant, and the microbes on the surface shrink in half an hour. It is difficult to model them through $3 \mathrm{D}$ scanning. After many demonstrations, we have decided to use 
photo-molding technology, and use microfocus shooting and Photoscan to complete the preliminary virtual simulation modeling. In order to meet the number of faces required for Unity application design, the number of faces of the model is reduced in Maya. The animation of the growth of germs is simulated by Houdini, and then synthesized in Maya. In order to adapt to Unity interactive application design, the abc file format is used. The virtual simulation of materials mainly simulates the effect of optical microscope and electron microscope, forming an innovative solution for agricultural science and technology content. New digital animation teaching content is generated, such as: modeling techniques for cystic stalks, sporangia, zoospores, microbial material solutions under the microscope, analysis of the movement laws of peronophythora litchii, and growth animation solutions for cystic stalks, etc.

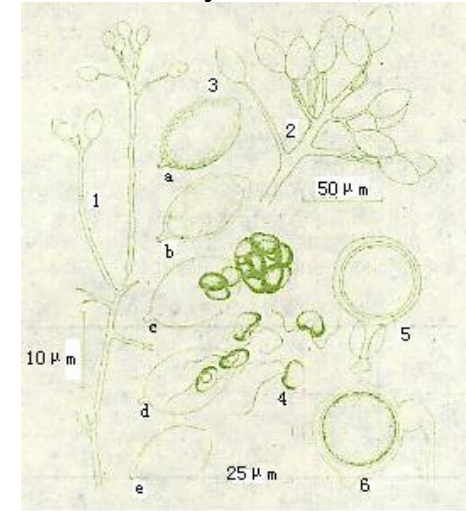

Figure1 Traditional Teaching Sketch Map

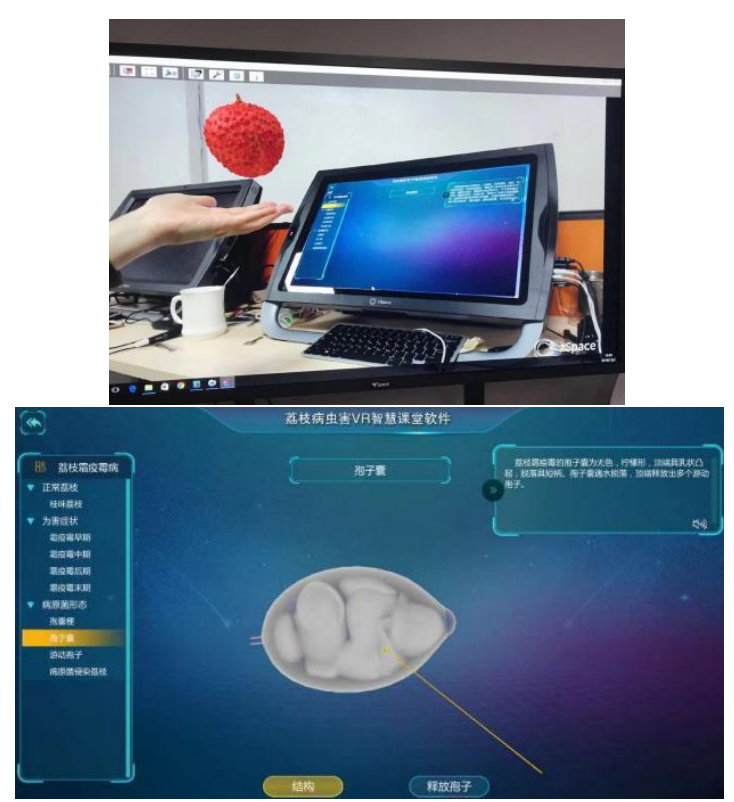

Figure2 VR Smart Teaching Sketch Map

The combination of digital animation and agricultural microbiology has also cultivated students' scientific research capabilities. Digital animation creation has relatively high requirements for the collection of visual information of the content, and the process of material collection promotes the in-depth exploration of microbial scientific research content in unknown fields. For example, how the zoospores fissioned in the sporangia before being released, there are no research results on its micro-moving state, which promotes the further expansion of the field of agricultural microbial research in unknown fields. Biotechnology content also brings new technical problems to the production process of digital animation. For example, zoospores swim very fast and it is difficult to capture the movement of their flagella under a microscope. In the process of animation creation, it is necessary to reason about its movement laws and movement states, and then form skeletal movement animation.

What animation students need most is imagination, innovation, and the ability to apply new knowledge. In the teaching process, teachers should put their vision outside the specialty and jump out of the professional barriers. Students' thinking will be inspired. In addition, in the process of participating in the project, teachers and students of animation majors not only improve their abilities, the project also has an impact on students' learning direction and teachers' teaching reform, providing new ideas for future professional development.

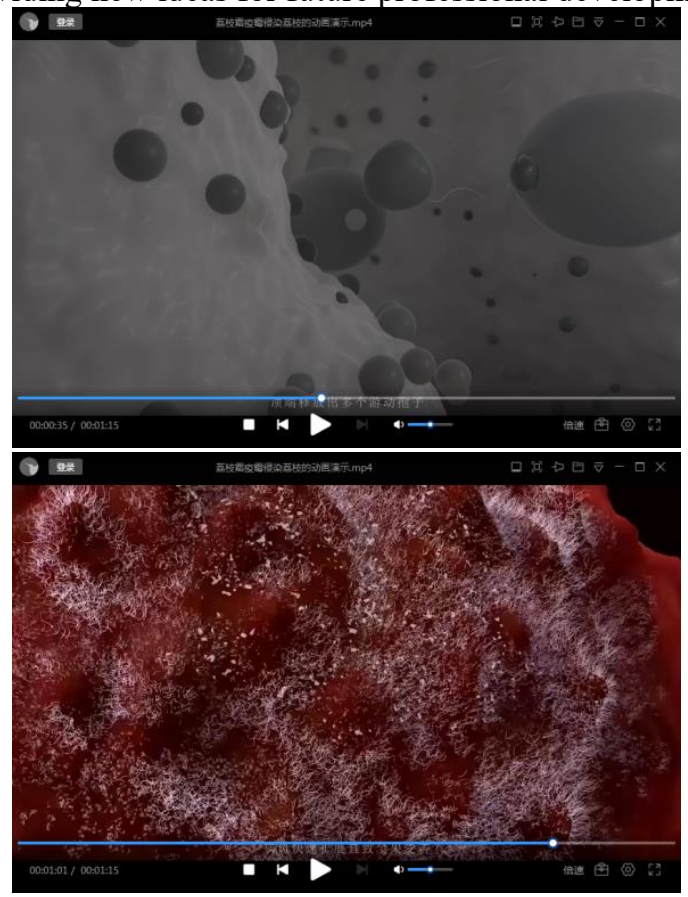

Figure3 Animation Screenshot of Litchii Infected by Peronophythora Litchii

\subsection{The Arts are Harmonized and the Disciplines are Unbounded}

The animation major belongs to the art major, and the agricultural microbiology belongs to the agricultural specialty discipline. The application of digital animation to the study of the role of microbiology in agriculture truly reflects China's idea of "one should be as tolerant as the vast ocean which admits hundreds of rivers". The two majors promote and advance each other in the process of mutual integration, and they have begun to try teaching reforms[15]. In microbiology observation, the time of observation is short and the amount of information acquired is relatively small. However, the digital 
animation process has a high requirement for visual information. Agricultural microbiology students need to observe carefully to understand the knowledge. In the process of transforming information, the teachers and students of animation major must have a certain understanding of microbial knowledge, master the basic structure and development process of microbiology. This is also an innovation for their own thinking, and they need to grasp the form of new object structures. For example, during the digital animation transformation of the zoospore fission process, in-depth observation of the fission process in the sporangia is needed.

"Knowledge is never lonely." There is a connection between any disciplines and any knowledge. The most fundamental connection is the connection with human production and life. Combining the animation specialty with agricultural microbiology can enhance the relevance and richness of knowledge. Colleges and universities, as the training grounds for cutting-edge talents, should also actively innovate and cultivate students' creativity, so as to meet the needs of the nation and society in cultivating comprehensive professional talents.

\section{Cooperation between Schools and Enterprises}

In the context of school-enterprise cooperation and collaborative education, through the "VR Smart Education: Animation + VR Curriculum Development" project research, digital animation and agricultural microbiology are combined, the teaching model is innovated, and modern VR curriculum application is used to plant this research results among them. The results are remarkable. There is little daily contact between the students majoring in animation and agricultural microbiology, and they are very curious about the learning content of their respective majors, and each side has their own gains during the cooperation process. Agricultural microbiology students are amazed that digital animation can make the boring knowledge of microbes and their relationship with agriculture so vivid and interesting, and animation students also feel that the microbial world is very rich and has an impact on their existing concepts. It provides a reference for further school-enterprise cooperation and deep integration between liberal arts disciplines and agriculture disciplines. School-enterprise cooperation and collaborative education promotes the product development of enterprises, and also promotes the teaching and research in colleges and universities.

\section{Conclusion}

College teaching should have innovation and representativeness of the times. The refined development of specialty does not conflict with interdisciplinary research. It is the two directions of deepening understanding of knowledge. Based on VR virtual reality technology, digital animation is integrated with agricultural microbiology to transform the micro world into macro images. Students in agricultural microbiology can understand the relevant knowledge more deeply, and students in animation majors can also get more professional practices, which will help to "improve quality and efficiency" which is a purpose of teaching and research, and is also a useful exploration of the construction of new liberal arts and new agricultural sciences in the field of interdisciplinary research. Using VR virtual reality technology to carry out interdisciplinary research on animation teaching and agricultural microbiology teaching, and develop new curriculum content can effectively enhance the effectiveness of teaching in various disciplines, and open up new teaching content and research ideas for animation and agricultural microbiology courses. Virtual reality technology and digital animation art provide interactive and immersive teaching experience for agricultural microbiology teaching and scientific research, and also inspire new ideas for new agricultural teaching research. Agricultural microbiology content provides research content for animation art creation and expands the space for technology research and development. Interdisciplinary curriculum development effectively promotes the development of new liberal arts and new agricultural teaching and research, and has become a new growing point for education and research in various disciplines.

\section{References}

1. The New Development of Learning Science and Instructional Design in the Technology Environment-Interview with Professor Richard Mayer, the Founder of Multimedia Learning Research [J]. Xue Wang, Zhijun Wang, Meiqi Han. China Electrification Education. 2019 (10)

2. Empirical Research on the Impact of Behavioral Involvement on Deep Learning__ Taking Video Learning in Virtual Reality (VR) as an Example [J]. Zheyu Liu, Zhijun Wang. Journal of Distance Education. 2017 (01)

3. Yi Li, Shigang Yan. On the Dilemma and Outlet of the Value of Technical Education [J]. Research on Electronic Education, 2007, (8): 9-12.

4. Yongsheng Xiang, Jinxiang Yuan. Research on the Operational Mechanism of Cooperative Education between Applied Colleges and Local Areas: Taking Four Independent Colleges in Zhejiang as Examples [J]. Heilongjiang Higher Education Research, 2019 (6).

5. Jianyun Zhang. Exploring the Production and Education Integration Education Mechanism in Secondary Vocational Schools Based on the Industry-Education Integration Park: Taking Yixing Middle Professional School as an Example [J]. Vocational and Technical Education, 2019 (15).

6. Feng Wang. Exploration of the Innovative Model of "School-Enterprise-School" Collaborative Vocational Education Based on Comprehensive Ability [J]. China Vocational and Technical Education, 2017 (26): 76-80. 
7. Juan Tian, Zhendong Sun. Misunderstandings and Rational Return of Interdisciplinary Teaching [J]. China Educational Journal, 2019 (4): 63-67.

8. Zhenchao Pang. Teaching Reform of Interdisciplinary Education [J]. University Education Science, 2019 (4).

9. Xue Cheng, Qingpu Zhang. Research on the Evaluation of Knowledge Interaction among Interdisciplinary Innovation Teams in Colleges and Universities [J]. Science \& Technology Progress and Policy, 2019, 36 (16).

10. Ning Qi. Problems and Countermeasures in Promoting Research Teaching in Universities [J]. Education and Occupation, 2016 (16).

11. Lei Zhang. Development and Teaching Practice of Interdisciplinary School Curriculum [J]. Biology Teaching, 2019 (8).

12. Ting Tong, Xiaotong Li. The Status quo and Development Path of Information Technology in Higher Education Animation Major Reform [J]. China Information Technology Education, 2013 (9): 113-114.

13. Qingbin Hou. Exploration of Animation Teaching Innovation under the Background of Information Technology [J]. Electronic Test, 2014 (S1): 86-88.

14. Li Wang, Lichao Zhao. Exploring the Educational Model of Interdisciplinary Collaborative Teaching and WIKI System Integration-Taking "Food Microbiology Inspection" Course as an Example [J]. Chinese Journal of Microbiology, 2018.

15. Zhuxin Hu, Guoxing Huang. Research and Implementation of 3D Virtual Digital Campus System [J]. Microcomputer Applications, 2007 (05): $5+32-34$. 